\section{A spin-labelling Nobel?}

SIR-Perestroika (restructuring) and glasnost (openness) in the Soviet Union have resulted in corresponding changes in the attitude of the world community towards the Soviet Union and the Soviet people. Does this process affect the Nobel prize committee? It is no secret that in the past there has been a prejudice against Russian and Soviet scientists as well as against scientific results coming out of Soviet laboratories. For example it is wellknown that Dmitryi Mendeleev lost out by only one vote to the discoverer of fluorine, Henry Moissan, winner of the Nobel prize in 1907 . Others passed over by the committee include Alexander Arbuzov, the founder of the chemistry of organophosphorus compounds (although Brown was awarded a Nobel prize for his studies of organic boron compounds); Alexander Braunstein, who elucidated the transamination reaction; Eugenyi Zavoisky, who discovered the phenomenon of electron para-magnetic resonance (a later work on nuclear magnetic resonance was marked by a Nobel prize). The Nobel prize committee honoured C. Raman instead of Mandelstam. The only Soviet Nobel prizewinner in chemistry was Nikolay Semenov, whose scientific discoveries were so significant that they could not be ignored.

My question is: can the Nobel prize committee now examine more carefully the discoveries made in the Soviet Union? The selection of prizewinners is up to the committee, but I would like to suggest the field of nitroxyl radicals and spin labelling as worthy of recognition. In this field, great results were achieved in the Soviet Union. Harden McConnell (Stanford University) was the first to work out spin labelling, and obtained important results in immunology and the study of membrane structure using this technique. However, the chemical basis of spin labelling is an unusual class of nitroxides, the nitroxyl radicals', and their nonradical reactions, discovered in the Soviet Union by Edward Rozantsev. (In France, André Rassat had also worked on nitroxyl chemistry.) Nitroxyl radicals have an 'extra' function, so can react without involving free valency, hence these novel free radical reactions ${ }^{2}$. When McConnell worked out the theory of spin labelling, he used nitroxyl radicals and their nonradical reactions in the preparation of spin-labelled biomacromolecules ${ }^{3}$.

Nitroxyl radicals are also widely used in chemical physics, chemical kinetics, analytical chemistry, polymer chemistry, and even in pharmacology. A few thousand papers, many reviews, and monographs ${ }^{4-7}$ have been devoted to nitroxyl radicals and spin labelling. Has the Nobel prize committee taken note of this novel area of chemistry (nitroxyls and spin labelling) and its founders: McConnell, Rozantsev and Rassat?

Institute for Biotechnology,

Moscow 117246, USSR

*Present address: Max-Planck Institut für medizinische Forschung 6900 Heidelberg 1, Jean-Strasse 29, FRG

1. Neiman, M.B., Rozantsev, E.G. \& Mamedova, Y.G. Nature 196, 472-473 (1962).

2. Rozantsev, E.G. Free Nitroxyl Radicals (Plenum, New York, 1970).

3. Stone, T.J., Buckman, T., Nordio, R.L. \& McConnell, H.M. Proc. natn. Acad. Sci. U.S.A. 54, 1010-1014 (1965).

4. Spin Labeling. Theory and Application (ed. Berliner, L.J.) Vols 1-3 (Academic, New York, 1976, 1979, 1989).

5. Spin Labeling Method. Problems and Outlooks (eds Emanuel, N.M. and Zhdanov, R.I.) (Nauka, Moscow, 1986).

6. Nitroxyl Radicals. Synthesis, Chemistry and Applications (eds Rozantsev, E.G. \& Zhdanov, R.I.) (Nauka, Moscow, 1987).

7. Biomacromolecules in Spin Labeling (eds Likhtenstein, G.I. \& Zhdanov, R.I.) (Nauka, Moscow, 1988).

\section{Hirohito's legacy}

SIR-Emperor Hirohito's role during his 63 -year reign will be debated for many years to come. The comment by Masakado Kawata and Eiich Kasuya (Nature 338, $370 ; 1989)$ fails to address the basic issue.

I think that Hirohito really wished to remain a peaceful emperor biologist but did not have a courage to overcome the very strong imperial court system and the military power, which fed him only information advantageous to themselves. If the Emperor chose not to cooperate with the military, they could have fabricated excuses to justify replacing him with a younger brother.

But two questions remain: what lessons have the Japanese learned from the Pacific War, and how will the new Emperor Akihito behave in the years to come? Although the monarch does not have any political power under the new constitution, he is still very influential as the national symbol. In recent years, his vulnerability to being used by those on the fanatical right wing seems to have increased. After Japan's surrender in 1945, Hirohito declared that he was not a god, and travelled around the country meeting people. That practice has, however, long been discontinued except for very ceremonial occasions. Although Akihito had the courage and determination to marry a commoner and to send his son to the University of Oxford, he may not be able to break the ever-thickening "chrysanthemum curtain'. If there is an attempt to use him for imperialist domination by military power, will he be able to resist? It remains to be seen how well-informed Emperor Akihito can keep himself and how fully he can express his thoughts.

11334 Pemmican Run,

SHIRO TANAKA

Cincinnati, Ohio 45249, USA

\section{Raw data}

SIR-Your report (Nature 339, 163; 1989) on the investigation into a paper published in Cell raises serious concerns. The integrity of the scientific process requires that raw data be recorded fully, promptly and accurately and stored securely. There must be a clear distinction between recording of experimental details and observations, and jottings of ideas or sketches of proposed studies, which an individual may choose to keep in a more casual way (not advisable in relation to claims to priority). In any case of doubt about the relationship between the data and the published conclusions, whether fraud or error is suspected, there should be no question of not carrying out an audit of the raw data. To facilitate this, laboratory notebooks and data files should generally be the property of the institution, and the director of the institution should be responsible for ensuring their security.

Few would wish to see a system such as good laboratory practice for the pharmaceutical industry imposed upon the basic research community. But the integrity of scientific research must not only be maintained but must be seen to be maintained. As Ephraim Racker states (Nature 339, 91-93; 1989), audits of data would have little effect on clever fraudsters, but such cases are thought to be very rare.

G. ALLEN

26 Chesham Crescent,

London SE2O 7RW, UK

\section{Is anybody there?}

SIR-Speculation regarding the search for extraterrestrial intelligence (SETI), should be accorded a legitimate place in both science and Nature. Astronomers have educed both theoretical and observational evidence of planetary systems associated with stars, and now more than ever, intelligent life may be presumed by respectable (if hopeful) scientists to occur commonly in the Universe. Intelligent life, therefore, may indeed have evolved in planetary systems within striking distance of supernova 1987A. Although this supernova constituted a bonanza for Earth's astronomers, supernovae may tragically extinguish 'nearby' intelligent life.

The interstellar psychologists among us might suggest the search for extraterrestrial transmissions upon stars in the vicinity of stars approaching the supernova stage. Just as we have launched records of our existence into deep space, intelligent beings who may be aware of impending disaster might be more likely than others not so threatened to transmit messages to posterity.

Ram Trac Corporation ROBERT A. MICHAELS

\section{Northumberland Drive,}

Schenectady, New York 12309, USA 